\title{
Endoscopic ultrasound-guided angiotherapy in bleeding gastrointestinal stromal tumors with coil deployment and cyanoacrylate injection
}

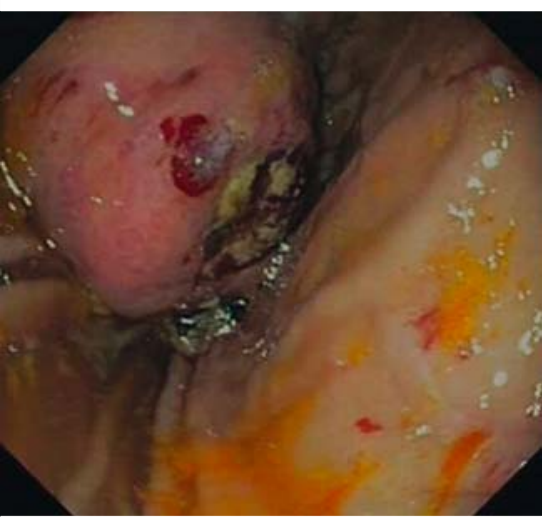

Fig. 1 Endoscopic view of the ulcerated bleeding $\mathrm{Gl}$ stromal tumor (GIST).

Hemorrhage is the most frequent (30$40 \%$ ) and dangerous complication of gastrointestinal stromal tumors (GISTs), with surgery being the treatment of choice and emergency surgery having a significantly higher risk than elective procedures [1]. Conventional endoscopic treatment of tumoral lesions is challenging and efficacy limited because of the complex neoangiogenesis of these lesions, which are beyond the reach of endoscopic contact procedures [2]. Cases of endoscopic ultrasound (EUS)guided therapy of bleeding GISTs with injection of cyanoacrylate (CYA) $[3,4]$ or ethanol [5] have been published. To the best of our knowledge, EUS-guided coil deployment has not been reported in this setting. We present two cases of bleeding GISTs successfully treated with EUS-guided combined coil deployment and further injection of CYA targeting the feeding artery ( $\bullet$ Video 1 ).

Case 1: a 72-year-old man was admitted for melena and hemodynamic instability. An ulcerated fundic mass with a necrotic center and a 5-mm intratumoral artery was observed ( $\mathbf{F i g . 1}$ ). EUS-guided injection of CYA (Histoacryl; B. Braun, Melsulgen, Germany) into the feeding artery ( $\vee$ Fig. 2) with a 22-gauge needle was the initial approach. However, a spurting

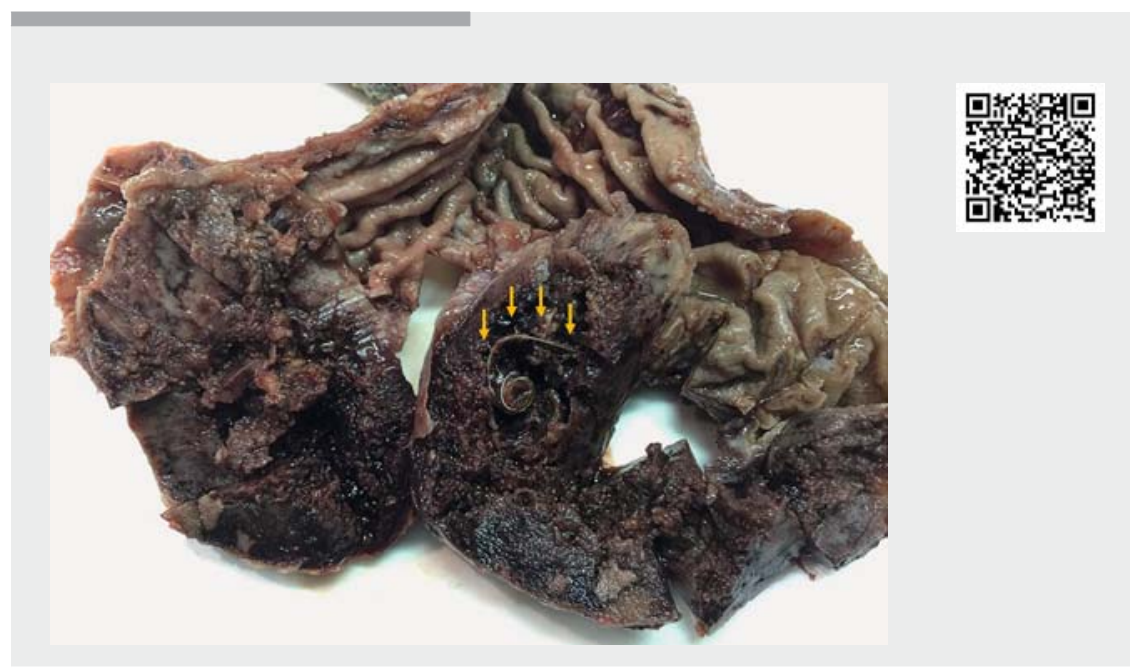

$\checkmark$ Video 1 Endoscopic ultrasound (EUS)-guided angiotherapy in two patients with bleeding GI stromal tumors with EUS-guided coil deployment and cyanoacrylate (CYA) injection targeting the feeding artery.

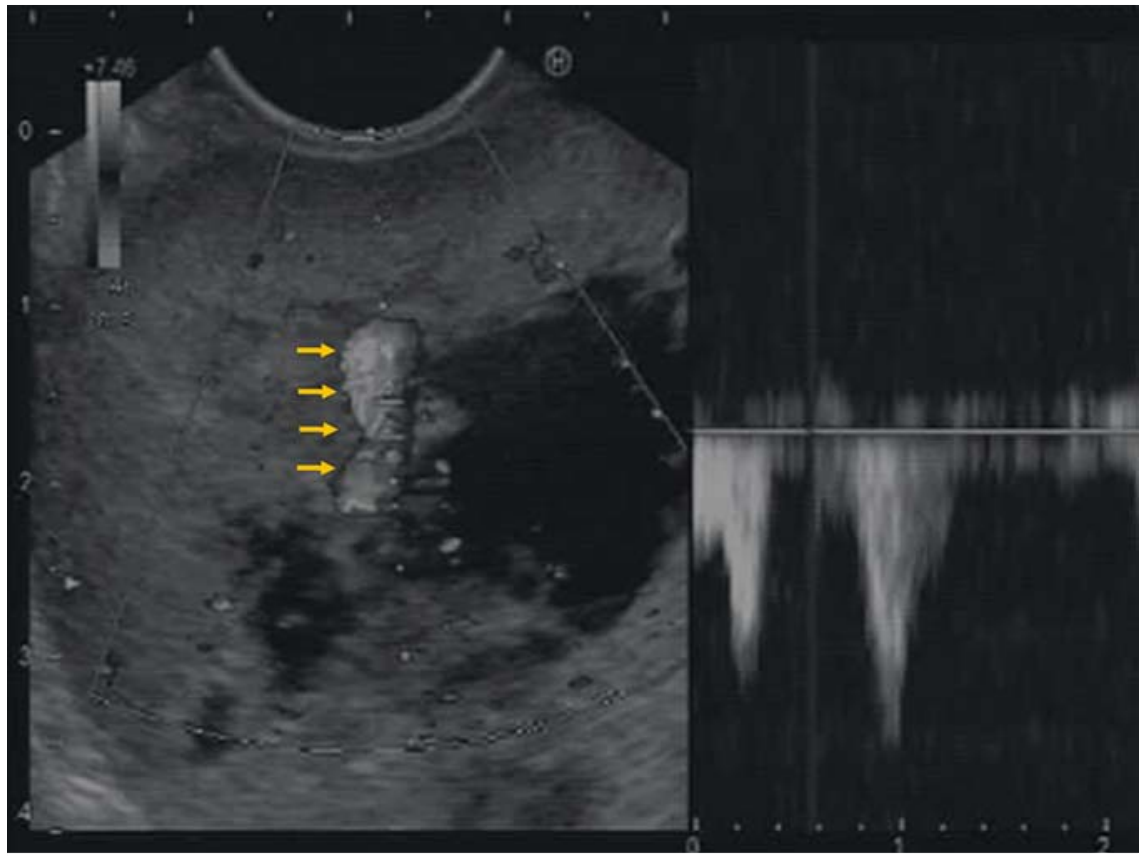

- Fig. 2 Endoscopic ultrasound (EUS) image displaying the feeding artery of the bleeding GI stromal tumor (GIST) (arrows) shown in $>$ Fig. 1

bleed into the tumor cavity after punction was observed ( $\boldsymbol{F}$ Fig. $\mathbf{3}$ ). Hemostasis was achieved by deploying a $6-\mathrm{mm} \times 20$ - cm coil (Nester; Cook Medical, Limerick, Ireland) and injecting $2 \mathrm{~mL}$ of CYA with a 19-gauge needle ( $\mathbf{F i g . 4}$ ). 


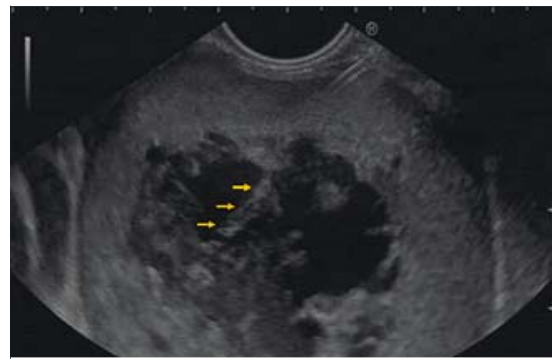

- Fig. 3 Spurting bleed (arrows) after the endoscopic ultrasound (EUS)-guided punction with a 22-gauge needle.

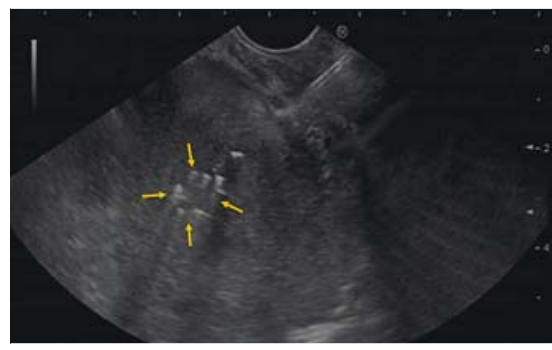

- Fig.4 Endoscopic ultrasound (EUS)guided deployed coil (arrows) with a 19gauge needle.

Case 2: a 79-year-old woman was admitted for hematemesis and hypovolemic shock. An ulcerated fundic mass with a 4-mm artery was observed. EUS-guided therapy with a 19-gauge needle was performed employing a $6-\mathrm{mm} \times 14-\mathrm{cm}$ coil, followed by injection of $2 \mathrm{~mL}$ of CYA.

The clinical outcome in both patients was uneventful, and scheduled surgery took place 4 weeks later.

EUS-guided combined angiotherapy targeting the culprit artery of bleeding GISTs maintained hemostasis until scheduled surgery. Moreover, although the follow-up in these two patients was short, EUS-guided angiotherapy may be a therapeutic option in patients with bleeding GISTs deemed unfit for surgery.

Endoscopy_UCTN_Code_TTT_1AS_2AG

\section{Competing interests}

The authors declare they have no conflict of interest.

The authors

Rafael Romero-Castro ${ }^{1,2}$, Victoria Alejandra Jimenez-Garciaa, ${ }^{1,2}$, Atsushi Irisawa ${ }^{3}$, Pedro Hergueta-Delgado ${ }^{1}$, Antonio Garrido-

Serrano ${ }^{1}$, Reyes Aparcero-Lopez ${ }^{1}$, Angel Caunedo-Alvarez

1 Virgen Macarena University Hospital, Endoscopy Unit, Gastroenterology Division, Seville, Spain

2 Vithas Nisa Seville Hospital, Endoscopy Unit, Seville, Spain

3 Department of Gastroenterology, Dokkyo Medical University School of Medicine, Tochigi, Japan

\section{Corresponding author}

\section{Rafael Romero Castro, MD}

Virgen Macarena University Hospital, Endoscopy Unit, Gastroenterology Division, Calle Dr. Fedriani, 3, 41009 Seville, Spain Fax: +34955008805 rafaromecas@hotmail.com

\section{References}

[1] Liu Q, Kong F, Zhou J et al. Management of hemorrhage in gastrointestinal stromal tumors: a review. Cancer Manag Res 2018; 10 : 735-743

[2] Venezia G, Asnaghi G, Manca A et al. Successful use of Hemospray as a bridge to surgery in life-threatening bleeding from a gastrointestinal stromal tumor of the stomach. Endoscopy 2016; 48: E232-E233

[3] Levy M], Wong Kee Song LM, Farnell MB et al. Endoscopic ultrasound (EUS)-guided angiotherapy of refractory gastrointestinal bleeding. Am J Gastroenterol 2008; 103: 352-359
[4] Kumbhari V, Gondal B, Okolo lii PI et al. Endoscopic ultrasound-guided angiotherapy of a large bleeding gastrointestinal stromal tumor. Endoscopy 2013; 45: E326-E327

[5] Valdivielso Cortazar E, Fernandez-Urien I, Vila Costas || et al. Endoscopic ultrasoundguided therapy of a gastrointestinal stroma tumor (GIST). Endoscopy 2015; 47: E262E263

\section{Bibliography}

Endoscopy 2021; 53: E124-E125

DOI 10.1055/a-1216-0634

ISSN 0013-726X

published online 24.7.2020

(C) 2020. Thieme. All rights reserved.

Georg Thieme Verlag KG, Rüdigerstraße 14, 70469 Stuttgart, Germany

\section{ENDOSCOPY E-VIDEOS}

https://eref.thieme.de/e-videos

Endoscopy E-Videos is a free access online section, reporting G.: on interesting cases and new techniques in gastroenterological endoscopy. All papers include a high quality video and all contributions are freely accessible online.

This section has its own submission website at https://mc.manuscriptcentral.com/e-videos 